infants were studied before 4 days would cause extra variability in blood pressure measurement.

In this study the mean systolic blood pressure increased by $1.5 \mathrm{~mm} \mathrm{Hg}$ /day within the short period of 4 to 6 days and $0.5 \mathrm{~mm} \mathrm{Hg} /$ week within the period of 5 to 7 weeks. Nevertheless, these increases were small compared with the overall rise in blood pressure $(20 \mathrm{~mm} \mathrm{Hg}$ ) between 4 to 6 days and 5 to 7 weeks.

We used the Parkes Doppler ultrasound system, which, we have found, measures only systolic blood pressure. ${ }^{3}$ Systolic and diastolic blood pressures are highly correlated, however, and, furthermore, systolic blood pressure is a better predictor of subsequent cardiovascular morbidity than diastolic blood pressure. ${ }^{10}$

We have found a highly significant, though weak, relation between infants' blood pressures at the age of 4 to 6 days and those at the age of 5 to 7 weeks. The relation is not strong, probably because of the high degree of variability of blood pressure that we have previously observed in the neonatal period.

Kass et al have shown that the blood pressure at the ages of 2 to 14 years is related to blood pressure when measured again four years later, at the ages of 6 to 18 years." Also, a familial aggregation of blood pressure may be shown by the age of 2 years. ${ }^{11}$ If our follow-up studies confirm that the relation that we have already found is maintained until the age of 2 years, it would suggest that the blood pressures of some people may be predetermined by the time they are 4 to 6 days old and that the tendency to hypertension may already be manifest by that age.

It is a pleasure to acknowledge the generous financial support of the Medical Research Council to Michael de Swiet and to the nurses, D Johnson, J Mitchell, F Smith, and E Szewvzyk; without their enthusiasm none of the measurements would have been made. We are grateful to Dr P Wallis and Dr P Swift for permission to study patients under their care, to $\mathrm{Dr} W$ Fox for invaluable criticism, and to Mrs $S$ Cowley for secretarial help.

\section{References}

Mial, W E, and Lovell, A G, British Medical fournal, 1967, 2, 660.

Zinner, S H, et al, American fournal of Epidemiology, 1974, 100, 437.

${ }^{3}$ Elseed, A M, Shinebourne, E A, and Joseph, M C, Archives of Disease in Childhood, 1973, 48, 932.

+ Swiet, M de, Fancourt, R, and Peto, J, Clinical Science and Molecular Medicine, 1975, 49, 557 .

'Swiet, M de, Peto, J, and Shinebourne, E A, Archives of Disease in Childhood, 1974, 49, 734

Wright, B M, and Dore, C F, Lancet, 1970, 1, 337.

Modanlou, H, et al, fournal of Paediatrics, 1974, 85, 553.

${ }^{8}$ Moss, A J, and Adams, F H, American fournal of Diseases of Children, 1964, 107, 489

${ }^{9}$ Kirkland, R T, and Kirkland, J L, fournal of Pediatrics, 1972, 80, 52.

${ }^{10}$ Kannel, W B, Gordon, T, and Schwartz, M J, American fournal of Cardiology, 1971, 27, 335.

11 Kass, E H, and Zinner, S H, Millbank Memorial Fund Quarterly Bulletin, 1969, 47, 143.

\title{
Adrenal aldosterone-producing adenoma: use of colonic potential in diagnosis and subtraction scanning technique for localisation
}

\author{
K E BRITTON, T J GOODWIN, W S PEART, M E SNELL
}

British Medical fournal, 1976, 2, 11-14

\section{Summary}

Primary hypoaldosteronism is a potentially curable cause of hypertension, and much interest has been shown in methods of diagnosing the associated hypokalaemic hypertension and localising the adrenal adenoma. In two patients the diagnosis of primary aldosteronism was confirmed by colonic potential measurement and the adenoma localised by a new subtraction technique for early adrenal imaging applied to the use of ${ }^{131} \mathrm{I}-19$ iodocholesterol. Both patients underwent adrenalectomy and in each case an adenoma was removed. Blood pressure and electrolyte levels returned to normal after operation. In one patient bilateral adrenal phlebography

Department of Nuclear Medicine, Middlesex Hospital Medical School, London W1N 8AA

K E BRITTON, MD, MRCP, consultant in nuclear medicine

Mount Vernon Hospital, Northwood, Middlesex HA6 2RN

T J GOODWIN, MRCP, consultant physician

St Mary's Hospital, London W2

W S PEART, MD, FRCP, FRS, professor of medicine

M E SNELL, FRCS, consultant surgeon had failed to show the tumour, and sampling of aldosterone concentrations in the adrenal veins had been unsatisfactory.

\section{Introduction}

Primary hyperaldosteronism was first recognised as a clinical syndrome 22 years ago. ${ }^{1}$ High blood pressure, persistently low concentrations of plasma potassium, and high plasma sodium concentrations were the main clinical and biochemical features in the first patient. A large adrenal adenoma was subsequently removed and the blood pressure and plasma electrolytes reverted to normal levels. Since this report there has been considerable interest in the diagnosis of hypokalaemic hypertension associated with primary hyperaldosteronism and in methods for localising the adenoma. We describe the clinical and biochemical features of two patients in whom the diagnosis was confirmed by colonic measurement and the adenoma was localised by a new subtraction technique for early adrenal imaging applied to the use of ${ }^{131}$ I-19-iodocholesterol.

\section{Methods}

PROTOCOL FOR MEASUREMENT OF COLONIC POTENTIAL

Colonic potential difference was determined by the methods of Edmonds and Godfrey ${ }^{2}$ and Efstratopoulos $e t$ al ${ }^{3}$ using a probe electrode of perspex tubing containing $4 \%$ agar jelly with $150 \mathrm{mmol} / \mathrm{l}$ 
sodium chloride in contact with a silver screw coated with silver chloride. The reference electrode was an ordinary metal ECG plate strapped on one wrist with electrode jelly to ensure good contact. The electrodes were connected to a battery-operated ionmeter $\mathrm{pH}$ meter (specific ionmeter, model 401-00, Orion Research Company, Mass, USA) in the $\mathrm{mV}$ expanded scale $( \pm 70 \mathrm{mV})$. With a proctoscope, the potential difference between the skin and a point in the rectal mucosa about $5-10 \mathrm{~cm}$ from the anal margin was measured. The measurement was repeated three or four times until steady readings were obtained. A similar procedure was carried out with the probe electrode applied to the perianal skin, and the colonic potential difference was obtained by subtracting the potential difference between the wrist and the perianal skin from that between the wrist and colonic mucosa. No correction for the trans-skin potential difference was made. ${ }^{2}$

PROTOCOL FOR ADRENAL IMAGING

To image the adrenals only three days after an injection of ${ }^{131}$ I-19iodocholesterol a kidney scan was first made to localise the region of the adrenals and was followed by a kidney, liver, and spleen scan using technetium-labelled compounds simultaneously with the ${ }^{131} I-$ iodocholesterol scan. Subtraction of the kidney, liver, and spleen scan from the iodocholesterol scan showed the adrenals clearly. ${ }^{4}$

On day 1 the patient received $1.5 \mathrm{mCi}^{131} \mathrm{I}$-iodocholesterol (Eurotope Services Ltd) injected intravenously; the day before she had received $120 \mathrm{mg}$ potassium iodide by mouth and the technique had been explained to her. On day $30.25 \mathrm{mCi}{ }^{99 \mathrm{~m}} \mathrm{Tc}$-sulphur colloid (Radiochemical Centre, Amersham) and $2.5 \mathrm{mCi} 99 \mathrm{~m} \mathrm{Tc}$-glucoheptonate (NEN Chemicals) were injected intravenously. After one hour the patient lay prone with a pillow under her abdomen. A medium-energy 55-hole collimator with $15-\mathrm{cm}$ focus was set $10 \mathrm{~cm}$ from the patient's back. The ${ }^{99 m} \mathrm{Tc}$ window was set at $130-190 \mathrm{KeV}$. The rapid kidney scan was made using a Selo Ds $4 / 4 \mathrm{~s}$ rectilinear scanner at $36 \mathrm{~mm}$ s, line spacing $4 \mathrm{~mm}$. From the rapid scan an area of less than 16 $16 \mathrm{~cm}$ was marked out with its base across the middle of the more inferior kidney and extending superiorly. $\mathrm{A}^{131}$ I second channel window was set at $315-515 \mathrm{KeV}$. The double isotope scan was made over the selected area at $8 \mathrm{~mm} / \mathrm{s}$, line spacing $2 \mathrm{~mm}$. The scanner was adapted to provide a two-channel paper tape output which enregistered the count rate from each channel and encoded end-of-line signals. The method of data processing the adrenal images has been described. ${ }^{5}$ is

The scan was then repeated using an Elscint whole-body scanner with a medium-energy 85 -hole VC2 collimator with a focal point at $11 \mathrm{~cm}$ and set $5 \mathrm{~cm}$ over the patient's back. Windows for ${ }^{99 \mathrm{~m}} \mathrm{Tc}$ and ${ }^{131} \mathrm{I}$ were set at $130-170 \mathrm{KeV}$ and $315-425 \mathrm{KeV}$ respectively. The Elscint incorporated a dual-memory hard-wired visual display processor with a cassette-tape data storage facility. Fixed fractions of one scan could be subtracted from the other by operation of a set of switches. Localisation of each adrenal on the subtracted scan allowed the setting up of a square region of interest over each and over an inter-renal background area. By switching from the subtracted to the original adrenal data while maintaining the position of the region of interest the original total count rate over each adrenal and the background area were given. The following values were then obtained: the ratio of the gland count rate to background $(\mathrm{A})$, the more active gland count rate as a percentage of the sum of the count rates of the two glands (B), and this percentage obtained after correcting each gland's count rate for that of the background area (C). Provisional normal ranges are: $\mathrm{A}<1 \cdot 30: 1 ; \mathrm{B}<53^{\circ}{ }_{\circ}$; and $\mathrm{C}<58^{\circ}{ }_{\circ}$.

Adrenal vein sampling and adrenal phlebography were performed by catheterisation of the adrenal vein via the femoral route. " Electrolyte concentrations were measured by autoanalyser, plasma aldosterone by the method of Mayes et $a l^{8}$ (normal range $100-330 \mathrm{pmol} / 1$ (3.6-11.9 $\mathrm{ng} / 100 \mathrm{ml}$ ) and plasma renin activity by the method of Boyd et al ${ }^{9}$ (lower normal limit $0.09 \mathrm{pmol} / \mathrm{l} / \mathrm{h}(100 \mathrm{pg} / \mathrm{ml} / \mathrm{h})$ ).

\section{Case 1}

This woman, born in 1929, had had high blood pressure during her three pregnancies. When she was 43 she had a transient episode of weakness and paraesthesiae of the left side lasting three days, and a similar incident occurred 18 months later. Blood pressure was found to be raised, being $200 / 100 \mathrm{~mm} \mathrm{Hg}$ lying, and $210 / 120 \mathrm{~mm} \mathrm{Hg}$ standing. No cardiac enlargement, evidence of cardiac failure, or focal neurological signs were noted on examination. The fundi appeared normal.
Investigations-The chest $x$-ray picture, electrocardiogram, and full blood count were normal. A mid-stream specimen of urine showed a trace of protein but no cells. Repeated plasma sodium values were: 137, 141, 140,142, 141, 140, and $139 \mathrm{mmol}(\mathrm{m} \mathrm{Eq}) 1$; and repeated plasma potassium values were: $2 \cdot 1,2 \cdot 4,2 \cdot 3,2 \cdot 7$, and $2 \cdot 4$

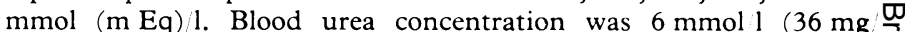
$100 \mathrm{ml}$ ); plasma bicarbonate $32 \mathrm{mmol}$ (m Eq) 1 ; urinary potassium $40 \mathrm{mmol} / 1$; and exchangeable potassium $34 \mathrm{mmol} \mathrm{kg}$. Colonic poten- $\mathbb{\mathbb { Q }}$ tial was $54 \mathrm{mV}$ (normal range -10 to $-35 \mathrm{mV}$ ); plasma renin activityc $0.028 \mathrm{pmol} / 1 / \mathrm{h}(30 \mathrm{pg} / \mathrm{ml} / \mathrm{h}) ;$ plasma aldosterone $1307 \mathrm{pmol} / \mathrm{l}(47 \mathrm{ng}$ $100 \mathrm{ml}$ ); and urinary aldosterone $100 \mathrm{mmol} 24 \mathrm{~h}(36 \mathrm{~g} / 24 \mathrm{~h}$ ) (normal range $10-70 \mathrm{mmol} / 24 \mathrm{~h}(3 \cdot 6-25 \mathrm{~g} / 24 \mathrm{~h}))$. On adrenal vein samplingo the left venous aldosterone concentration was $57236 \mathrm{pmol} / 1$ (2063 ng/을 $100 \mathrm{ml})$, that in the right vein was $4835 \mathrm{pmol} /(174 \mathrm{ng} 100 \mathrm{ml})$, $\bar{c}$ and the simultaneous cortisol concentration was $828 \mathrm{fmol} 1$ ( $30 \mathrm{pg} \overparen{\mathbb{D}}$ $100 \mathrm{ml}$ ) from both veins. Adrenal phlebography showed stretching of the upper pole veins of the left adrenal gland. Adrenal scanning con-ळ firmed a tumour in the left gland (fig 1). Measurement of the left $\vec{\circ}$ adrenal activity gave values: $\mathrm{A}=2 \cdot 2, \mathrm{~B}=54.5^{\prime \prime}$, and $\mathrm{C}=58.9^{\circ}{ }^{\circ}$. $\mathrm{B}$ and $\mathrm{C}$ were borderline values but $\mathrm{A}$ pointed unequivocally to in- $\vec{\omega}$ creased uptake by the left adrenal.

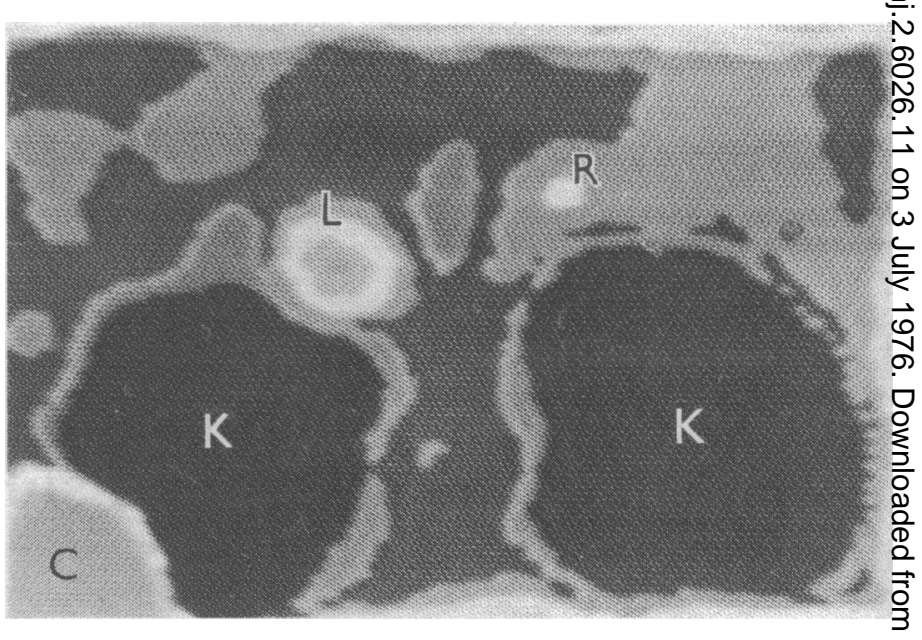

FIG 1 -Back as viewed from the detector showing the left $(\mathrm{L})$ and right $(\mathrm{R}) \rightleftharpoons$ adrenal images in white, the subtracted kidneys $(\mathrm{K})$ in black and colonic activity $(\mathrm{C})$. Left adrenal image has central darker area representing much higher activity than that of the right; this is compatible with a functioning adenoma of the left adrenal and a normal right adrenal. (Black and white representation of colour display.)

Course and treatment-The patient was treated with spironolactone $100 \mathrm{mg}$ three times a day for four weeks. The blood pressure and electrolyte levels reverted to normal. Left adrenalectomy was per-N formed and a $2-\mathrm{cm}$ adenoma was found in the posterolateral part of ${ }_{D}$ the gland. The gland weighed $8 \mathrm{~g}$ and contained a well-circumscribedo yellow nodule $1.5 \mathrm{~cm} \times 1.5 \mathrm{~cm} \times 0.7 \mathrm{~cm}$. Histology confirmed an adrenal cortical adenoma. During follow-up her blood pressure re- $\mathrm{O}$ mained normal at $130 / 80 \mathrm{~mm} \mathrm{Hg}$. Electrolytes were also normal (sodium $139 \mathrm{mmol} / 1$ and potassium $4.5 \mathrm{mmol} / 1$ ). Plasma renin activityo was $0.42 \mathrm{pmol} / 1 / \mathrm{h}(462 \mathrm{pg} / \mathrm{ml} / \mathrm{h})$, plasma aldosterone concentration $153 \mathrm{pmol} / 1(5.5 \mathrm{ng} / 100 \mathrm{ml})$, and colonic potential $-18 \mathrm{mV}$; all these values were normal.

\section{Case 2}

Hypertension occurred during the second and third pregnancies $\stackrel{\mathbb{D}}{2}$ of this woman, born in 1934, and she had had a persistently raised blood pressure since her last pregnancy. She complained of occasionalo generalised headache. She had a strong family history of cardiovascularo and cerebrovascular disease. Previous drug treatment included propranolol, Moduretic (hydrochlorthiazide and amiloride hydro- $\frac{\overline{ }}{\bar{T}}$ chloride), and debrisoquine. On examination the blood pressure was? $198 / 100 \mathrm{~mm} \mathrm{Hg}$ lying and $176 / 120 \mathrm{~mm} \mathrm{Hg}$ standing. No cardiac enlargement or signs of failure were noted. The fundi showed arteriovenous nipping.

Investigations-The chest $x$-ray picture and full blood count were normal. Electrocardiography showed minor S-T depression in 
anterolateral leads. A mid-stream specimen of urine showed no protein and no cells. Blood urea concentration was $4 \mathrm{mmol} / \mathrm{l}(24 \mathrm{mg} /$ $100 \mathrm{ml}$ ). Intravenous pyelography and renography showed nothing abnormal. Repeated plasma sodium values were: 141,136 , and 142 $\mathrm{mmol} / \mathrm{l}$; and repeated plasma potassium values were: $2 \cdot 8$, and $3 \cdot 4$ $\mathrm{mmol} / \mathrm{l}$; plasma bicarbonate concentration was $30 \mathrm{mmol} / \mathrm{l}$; urinary potassium $25 \mathrm{mmol} / \mathrm{l}$; and colonic potential $-38 \mathrm{mV}$. Plasma renin activity was $0.56 \mathrm{pmol} / \mathrm{l} / \mathrm{h}(62 \mathrm{pg} / \mathrm{ml} / \mathrm{h})$. Frusemide $40 \mathrm{mg}$ intravenously caused the renin activity to rise from $0.045 \mathrm{pmol} / \mathrm{l} / \mathrm{h}$ $(49 \mathrm{pg} / \mathrm{ml} / \mathrm{h})$ to $0.09 \mathrm{pmol} / \mathrm{l} / \mathrm{h} \quad(100 \mathrm{pg} / \mathrm{ml} / \mathrm{h})$. Repeated plasma aldosterone estimations showed concentrations of: 1070, 1260, and $560 \mathrm{pmol} / \mathrm{l}(38,45$, and $20 \mathrm{ng} / 100 \mathrm{ml})$. On adrenal vein sampling the left venous aldosterone concentration was $1460 \mathrm{pmol} / 1$ ( $52.6 \mathrm{ng} /$ $100 \mathrm{ml}$ ) and no sample was obtained from the right vein. Bilateral adrenal phlebography showed no evidence of tumour even in retrospect. Adrenal scanning showed a tumour on the right side (fig 2). Measurement of right adrenal activity gave values: $A=1 \cdot 69, B=57 \cdot 8^{\circ}$, , and $C=74.5^{\circ}$. . These values were well outside the provisional normal range.

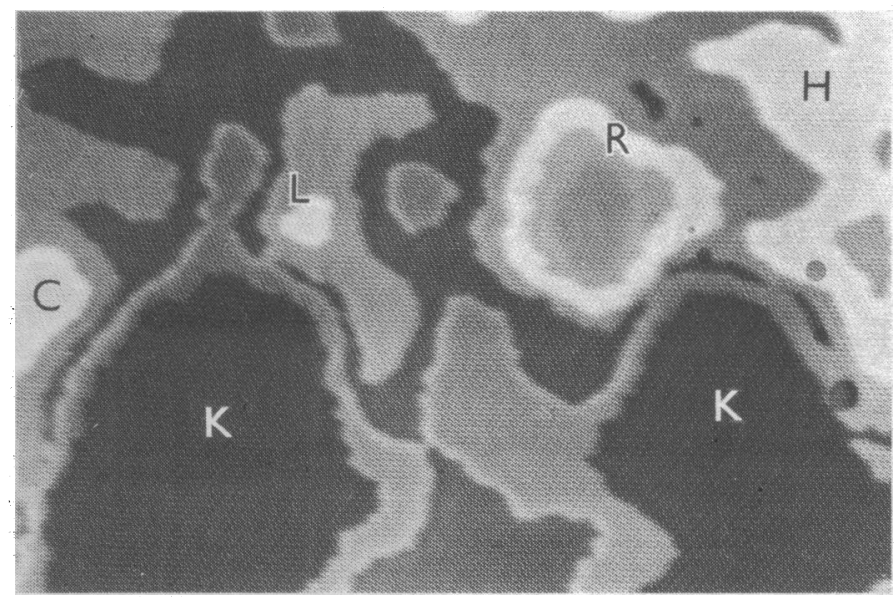

FIG 2-Back as viewed from detector showing left $(\mathrm{L})$ and right $(\mathrm{R})$ adrenal images in white, subtracted kidneys $(K)$ in black, hepatic activity $(H)$ and colonic activity (C). The right adrenal image has central darker area representing much higher activity than that of the left; this is compatible with functioning adenoma of right adrenal with normal left adrenal. (Black and white representation of colour display.)

Course and treatment - Initially this patient was given spironolactone and then amiloride and hydrochlorothiazide combined as two tablets daily for one month. Right adrenalectomy was carried out, and a gland containing a yellow nodule was removed. The gland weighed $12 \mathrm{~g}$ and measured $5 \times 3 \times 1.5 \mathrm{~cm}$. Histological examination confirmed a well-demarcated adrenal cortical adenoma. During follow-up her blood pressure $(120 / 80 \mathrm{~mm} \mathrm{Hg}$ ) and electrolyte levels (plasma sodium 138 and $136 \mathrm{mmol} / \mathrm{l}$; plasma potassium 4.1 and $3.9 \mathrm{mmol} / \mathrm{l}$ ) were normal. Plasma renin activity was $0.18 \mathrm{pmol} / \mathrm{l} / \mathrm{h} \quad(200 \mathrm{pg} / \mathrm{ml} / \mathrm{h})$. Plasma aldosterone concentration $(75 \mathrm{pmol} / 1(2.7 \mathrm{ng} / 100 \mathrm{ml}))$ and colonic potential $(-12 \mathrm{mV})$ were normal.

\section{Discussion}

Primary hyperaldosteronism is a potentially curable cause of hypertension. In its diagnosis much emphasis has been laid on the classical biochemical findings of hypokalaemia, hypernatraemia, inappropriate urinary excretion of potassium, high urinary and plasma aldosterone levels, and low plasma renin levels. With some or all of these findings exploratory laparotomy and direct visualisation of the adrenal glands have been recommended. Alternatively, adrenal vein catheterisation and phlebography have been performed. ${ }^{7}$ Such procedures are not without risk $^{10}$; Bookstein et $a l^{11}$ noted that the adrenal gland in Conn's syndrome .was particularly liable to rupture during phlebography. Recently Fukuchi et al $^{12}$ have devised a way of obviating the need to insert a catheter into both adrenal veins in order to lateralise increased aldosterone output.

Many complex methods are applicable to the diagnosis of primary aldosteronism, ${ }^{13}$ including quadric analysis. ${ }^{14}$ We have placed emphasis on the value of two newer techniques. The first is colonic potential difference measurement and the other is radionuclide adrenal scanning.

The use of colonic potential measurements was first described in patients by Edmonds and Godfrey," and its further application in the screening of primary hyperaldosteronism was described by Edmonds and Richards in $1970 . .^{15}$ Recently Beevers et $a^{16}$ were unable to recommend colonic potential measurement as a screening test. They found that four of their eight patients with subsequent proved hyperaldosteronism had normal values. They also found that four out of eight patients without apparent aldosterone excess had abnormally high colonic potential values. Our own experience in these two cases is that colonic potential measurement is still a very good screening test. In a further unpublished series of 33 patients one of us (TJG) found that out of all the investigations performed, including biochemical and radiological investigations, colonic potential measurements produced the most consistently abnormal values. These 33 patients had low plasma renin activity (less than 0.09 $\mathrm{pmol} / \mathrm{l} / \mathrm{h}(100 \mathrm{pg} / \mathrm{ml} / \mathrm{l})$. Sixteen of the $33 \mathrm{had}$ a colonic potential measurement of $-34 \mathrm{mV}$ or more. Of these 16 , seven were found to have tumours at operation, one had Cushing's syndrome, one consumed large amounts of liquorice, two were lost to follow-up, and the other five were undergoing further study.

Conventional methods of localising the adrenal adenoma were used in both our patients; in the second patient adrenal venous aldosterone sampling was unsatisfactory, and technically adequate adrenal phlebography failed to show the tumour.

${ }^{131}$ I-19-iodocholesterol made adrenal imaging a reality. ${ }^{17-21}$ Its disadvantages, however, are evident. A delay of five or more days is usually recommended between intravenous injection and imaging, by which time the ${ }^{131} \mathrm{I}$ has decayed considerably. The delay is recommended so that the $2^{\circ} \%$ uptake of iodocholesterol in the adrenal can be shown against the very high initial background activity in the adrenal environment. Iodocholesterol is concentrated above blood background in the liver and spleen and free ${ }^{131} \mathrm{I}$ from its metabolic breakdown is evident in the kidney and gut. Owing to its relatively poor uptake by the adrenals $1-2 \mathrm{mCi}$ has to be administered to give measurable count rates, but consequently there is a radiation dose of about 30 rads to the adrenals and about 1 rad to the gonads per $\mathrm{mCi}^{22} 23$ - equivalent to the gonadal dose of two intravenous pyelograms.

To optimise adrenal imaging certain simple principles have been implemented. Firstly, a kidney scan is used to locate the adrenals. Secondly, the adrenals tend to be at a fairly fixed depth $(5-8 \mathrm{~cm})$ from the skin of the back, so the collimated detector of a rectilinear scanner focused to this depth is used since it is more efficient in this respect than a gamma-camera. Thirdly, when the site of the adrenal is known, performing a very slow scan with narrow line spacing over the delineated small area is more efficient than encompassing half the patient's back. Fourthly, the adrenal takes up cholesterol continuously; therefore early imaging at three days makes more efficient use of the injected radionuclide, and the high background activity is accounted for by subtraction of a combined liver, spleen, and kidney scan. We have, in fact, shown an adrenal adenoma as early as two hours after injection using our technique. Lastly, since with an efficient subtraction technique early adrenal imaging is possible, substitution of ${ }^{123} I$ for ${ }^{131} I$ in iodocholesterol will bring the benefits of higher activity with lower radiation hazard. This would enable more widespread use of suppression tests, which require repetition of the scan, to distinguish the normal from the equivocally abnormal. Demonstration by adrenal scanning of the effect of suppression tests, ${ }^{24}$ lack of functioning tissue, ${ }^{25}$ reactivation of adrenal remnants, ${ }^{26}$ and functioning adrenal carcinoma ${ }^{27}$ clearly mimic the multiplicity of features already familiar in thyroid scanning. A programme has been 
initiated with the Atomic Energy Research Establishment, Harwell, who can produce ${ }^{131} \mathrm{I}$ free of ${ }^{124} \mathrm{I}$, to tackle the production of ${ }^{123}$ I-iociocholesterol and the more favoured iodocholesterol methyl derivative. ${ }^{28-29}$ Implementation of this suggestion would bring adrenal imaging into the realm of a routine screening test.

Proof of cure of primary aldosteronism can be assessed only after surgical correction. The two patients described have been followed up for a year and both have remained normotensive with a normal electrolyte pattern.

\author{
References \\ ${ }^{1}$ Conn, J W, fournal of Laboratory and Clinical Medicine, 1955, 45, 661. \\ 2 Edmonds, C J, and Godfrey, R C, Gut, 1970, 11, 330. \\ ${ }^{3}$ Efstratopoulos, A D, Peart, W S, and Wilson, G A, Clinical Science and \\ Molecular Medicine, 1974, 46, 489. \\ ${ }^{4}$ Britton, K E, paper presented at British Nuclear Medicine Society Annual \\ Meeting, 1974. \\ ${ }^{5}$ Britton, K E, in Proceedings of Nuclear Medicine Symposium, ed K H \\ Ephraim, and H Y Oei, p 107. Utrecht, State University Publications, \\ 1975. \\ ${ }^{6}$ Britton, K E, et al, Proceedings of the 13th International Meeting of the \\ Society of Nuclear Medicine, ed T Munkner, p 29.1. Copenhagen, Fadls \\ Forlag, 1975. \\ 'Sutton, D, British fournal of Radiology, 1975, 48, 237.
}

${ }^{8}$ Mayes, D, et al, fournal of Clinical Endocrinology and Metabolism, 1970, 30, 682 .

${ }^{9}$ Boyd, G W, et al, Lancet, 1969, 1, 213.

10 Bayliss, R I S, Edwards, O M, and Starer, F, British fournal of Radiology, 1970, 43, 531.

11 Bookstein, J J, Conn, J, and Reuter, S R, Radiology, 1968, 90, 778.

1.2 Fukuchi, S, et al, Clinical Science and Molecular Medicine, 1975, 49, 187 .

${ }^{13}$ Conn, J W, in Hypertension: Mechanisms and Management, ed G Onesti, E K Kwan, and J M Moyer, p 471. New York, Grune and Stratton, $\mathbb{Q}$ 1973

11 Aitchison, J, et al, American Heart fournal, 1971, 82, 660.

15 Edmonds, C J, and Richards, P, Lancet, 1970, 2, 624.

${ }^{16}$ Beevers, D G, et al, Gut, 1975, 16, 36.

17 Beierwaltes, W H, et al, fournal of Nuclear Medicine, 1969, 10, 387. is Conn, J W, et al, Fournal of Clinical Endocrinology and Metabolism, 1971 ,
33, 713 .

19 Lieberman, L M, et al, New England fournal of Medicine, 1971, 285, $1387 \frac{\text { S }}{\text { D }}$

20 Jorgensen, H, Norman, N, and Sundsfijord, J A, Acta Medica Scandinavica, 1975, 197, 345.

${ }^{21}$ Petersen, H D, et al, Acta Endocrinologica, 1975, 80, 81.

22 Kirschner, A S, Ice, R D, and Beierwaltes, W H, fournal of Nuclear $\vec{\circ}$ Medicine, 1973, 14, 713 .

${ }^{23}$ Beierwaltes, W H, et al, fournal of Nuclear Medicine, 1974, 15, 246.

${ }^{24}$ Conn, J W, et al, Archives of Internal Medicine, 1972, 129, 417.

${ }_{25}$ Conn, J W, and Cohen, E L, Archives of Internal Medicine, 1973, 131, 554 O

${ }^{26}$ Schteingart, D E, et al, Archives of Internal Medicine, 1972, 130, 384.

27 Forman, B H, et al, fournal of Nuclear Medicine, 1974, 15, 332.

${ }^{28}$ Kojima, M, et al, fournal of Nuclear Medicine, 1975, 16, 666.

29 Sarkar, S D, et al, Fournal of Nuclear Medicine, 1975, 16, 1038.

\title{
Mecillinam: a new antibiotic for enteric fever
}

\author{
P D CLARKE，A M GEDDES，D MCGHIE，J C WALL
}

British Medical fournal, 1976, 2, 14-15

\section{Summary}

Mecillinam is a new antibiotic related to the penicillins but more active than ampicillin against salmonellae, including Salmonella typhi. Mecillinam must be administered parenterally, but the ester, pivmecillinam, is absorbed from the gut. Eight patients suffering from typhoid fever and one suffering from paratyphoid fever were treated with the antibiotic, and seven responded satisfactorily. One patient could not tolerate pivmecillinam because of vomiting but there were no other adverse reactions. Serum and bile levels of mecillinam were many times the minimum inhibitory concentrations for most salmonellae. The antibiotic is a promising addition to the agents available for treating typhoid.

\section{Introduction}

Mecillinam (FL 1060) is a recently introduced 6- $\beta$-amidinopenicillanic acid antibiotic that is closely related to the penicillins but has a different mode of action and chemical structure. ${ }^{1 \cdot 2}$ It is a substituted formamidine compound and is $6-\beta$-(hexahydro$1 \mathrm{H}$-azepin-l-yl) methyleneamino penicillanic acid. Mecillinam

\footnotetext{
Department of Communicable and Tropical Diseases, East Birmingham Hospital, Birmingham B9 5ST

P D CLARKE, BM, MRCP, surgeon lieutenant commander, RN (present address: Royal Naval Hospital, Haslar, Portsmouth)

A M GEDDES, MB, FRCPED, consultant physician

Regional Public Health Laboratory, East Birmingham Hospital, Birmingham B5 9ST

D MCGHIE, MB, DIPBACT, senior microbiologist

J C WALL, FIMLS, senior technician
}

is not absorbed from the gastrointestinal tract, but for orab treatment the pivaloloxymethyl ester, pivmecillinam, which is hydrolysed enzymatically to mecillinam after absorption, i\$ satisfactory. Mecillinam is highly active against Escherichia coli $\overrightarrow{\vec{F}}$ including strains that are resistant to ampicillin. ${ }^{3}$ It has beens used successfully for treating urinary tract infection. ${ }^{+}$It is verye active against salmonellae; and a few patients suffering fromp. typhoid fever have been successfully treated with the antiobitic.

We report here the use of mecillinam in nine patients suffering from enteric fever.

\section{Patients and methods}

Nine patients, aged 7 to 53 years, who were suffering from typhoid or paratyphoid fever were selected for treatment with mecillinam. Alh were admitted to East Birmingham Hospital and the diagnosis was confirmed by culture of Salmonella typhi from the blood of eight patients and Salmonella paratyphi $A$ from the blood of the ninth Eight of the nine patients were seriously ill. It was therefore considered necessary to initiate treatment with mecillinam either by intramusculan (IM) or intravenous (IV) injection.

When a clinical response had been obtained treatment was changed to oral pivmecillinam. The ninth patient, who had previously receive typhoid-paratyphoid A and B immunisation and was not seriously ill was treated throughout with the oral preparation. The antibiotic was ${ }^{+}$ given in a dose of $400 \mathrm{mg}$ every six hours except in two children aged 8 in whom the dose was $200 \mathrm{mg}$ and one adult in whom it was $600 \mathrm{mg}$ ? Treatment was continued for 14 days and all patients remained in? hospital for at least a further two weeks, during which time specimensD of urine and stool were collected for culture. The patients were not discharged until at least six specimens were negative for the infecting organism. Further follow-up at home was arranged by the publiof health authorities. Tests of liver and renal function, together with fule blood counts, were performed before, during, and after mecillinan. treatment.

The minimum inhibitory concentrations (MICs) of the infecting organisms for mecillinam were measured by the agar incorporation method using Wellcotest agar. In one patient serial serum concentrations of mecillinam were measured after $600 \mathrm{mg}$ of the antibiotic had been given by IV injection and again after IM injection. 